\title{
Stimulant Methamphetamine and Dextromethorphan Use Among Thai Adolescents: Implications for Health of Women and Children
}

\author{
Chulathida Chomchai • Boonying Manaboriboon
}

Published online: 4 May 2012

(C) American College of Medical Toxicology 2012

\begin{abstract}
For over a decade, amphetamine-type stimulants have made their way into the adolescent culture of Thailand. Coupled with the more recent emergence of the legal, overthe-counter cough medicine dextromethorphan (DM), they represent the most commonly abused substances among Thai youths today. Methamphetamine is the second most popular drug of abuse in Thailand, the first being cannabis. It is available in the crystalline version, ICE, and the less pure methamphetamine tablets. The tablets are frequently crushed and smoked. Its use has gained enormous popularity among teenagers and young adults, including women of child-bearing age. As such, it has become the most common drug being detected in the urine of peripartum women, resulting in peripartum and postpartum complications for both mother and child. DM is a newer drug which has gained popularity among middle school and high school students due to its easy availability as a single product over the counter. It is usually taken with soft drinks at parties and gathering. It is metabolized by CYP4502D6 to dextrorphan, the substance responsible for the feeling of euphoria. Consequently, those who are poor metabolizers often experience the "negative" effects associated with the drug. The
\end{abstract}

This manuscript is based on a talk given as part of the ACMT Symposium on Recreational Drugs at the 2011 APAMT Congress in Penang, Malaysia.

C. Chomchai

Mahidol University International College,

999 Buddhamonton Sai 4 Road,

Salaya, Nakorn Pathom 73170, Thailand

e-mail: sicgt@mahidol.ac.th

B. Manaboriboon $(\square)$

Department of Pediatrics Siriraj Hospital, Mahidol University,

2 Prannok Road, Bangkok Noi,

Bangkok 10700, Thailand

e-mail: sibmn@mahidol.ac.th recreational use of methamphetamine and dextromethorphan in teenagers and young adults in Thailand is a serious problem. Recognizing not only the toxicological but also the emotional and psychosocial impacts of these drugs on Thai youth is an integral part of approaching the problem.

Keywords Methamphetamine - Dextromethorphan · Adolescent $\cdot$ Recreational drugs $\cdot$ Thailand

\section{Introduction}

For over a decade, amphetamine-type stimulants (ATS) have made their way into the adolescent culture of Thailand. Coupled with the more recent emergence of the legal, over-the-counter cough medicine dextromethorphan (DM), they represent the most commonly abused substances among Thai youths today. Their physical, emotional, and psychosocial impacts are felt not only by the teenagers themselves but also by their families, schools, and communities.

\section{Methamphetamine: The Tried and True Illicit High \\ History of Methamphetamine in Thailand}

Originally called "Ya Ma" or "horse tablet" in Thai, the original amphetamine manufactured by the Wellcome Foundation had a horse emblem on it. The name gained popularity among young male truck drivers and farmhands for its stimulant effect, allowing them to combat fatigue and work for longer periods of time. In 1996, the Thai Ministry of Public Health changed the drug's name to "Ya Ba" or mad medicine in the attempt to give a negative connotation to the 
drug which had been implicated in several cases of severe hallucinations and psychotic behavior $[1,2]$.

Who are the Users of Methamphetamine?

Most ATS are manufactured in the Southeast Asian region, particularly methamphetamine, thus making them highly accessible. For population ages 15-64 years, methamphetamine is the second most popular drug of abuse in Thailand, the most popular being cannabis [3]. Methamphetamine is also the primary substance of abuse in $82 \%$ of Thais seeking treatment for addiction in 2009. Data from the Thayarak Hospital Drug Treatment and Rehabilitation Center from 2006 to 2010 show that, while the largest group (approximately $20 \%$ ) seeking treatment comprised 15 - to 19 -year-olds, the proportion of 0 - to 14 -year-olds seeking treatment has grown from $8 \%$ in 2006 to nearly $14 \%$ in 2010 [4]. In a survey of 15- to 21-year-old vocational students in Northern Thailand, the prevalence of having ever used methamphetamine is $41 \%$ [5].

Types and Mode of Abuse of Methamphetamine in Thailand

Amphetamine can be ingested, smoked, snorted, or injected. Methamphetamine in Thailand is available mainly as crystal methamphetamine, or ICE, and methamphetamine pills in which pure methamphetamine has been adulterated with other substances and made into pill form. In Thailand, the most popular method of use is by smoking crushed methamphetamine tablets from either the tin foil lining from a cigarette pack or specially formulated bamboo straws [6]. The smoke is inhaled in a fashion similar to the "chasing the dragon" method described for heroin users [7]. Price remains the biggest factor influencing the drug's popularity. One tablet of methamphetamine is sold for 200 THB on the street, while a gram of ICE is sold for nearly 2,000 THB (65 USD, 49 Euro, 41 GBP). In 2005, The Regional Medical Center 10 in Chiang Mai Province studies the constituents of methamphetamine tablets confiscated in the area. They are found to have at least 19 colors with seven variable emblems, most of them with the letters WY, and containing an average of $23.32 \pm 9.01 \mathrm{mg}$ of methamphetamine per $100 \mathrm{mg}$ tablet. The rest of the tablet is adulterated by other stimulants such as caffeine, theophylline, or ephedrine. A more recent analysis of the pills shows methamphetamine content to be declining to as little as $15 \mathrm{mg}$ per $100 \mathrm{mg}$ tablet [4].

Methamphetamine in Special Populations: The Pregnant Woman and Her Infant

Smoked methamphetamine is also associated with high-risk sexual behaviors such as unprotected sexual intercourse.
Almost $15 \%$ of methamphetamine users who are in a rehabilitation program are under the age of 18 years [6]. Since the year 2001, Yaba has become the most common illicit substance found in the urine of antenatal women at Siriraj Hospital, Bangkok, Thailand. According to the hospital's data, pregnant women under the age of 18 years make up nearly $30 \%$ of this population. Typically, the majority of these women do not obtain prenatal care $(72 \%)$, and nearly $40 \%$ are unwilling to take the infant home after delivery [8].

Methamphetamine has also been found to cross the placenta and is excreted significantly in breast milk. Bartu et al. [9] assayed methamphetamine and amphetamine concentration in breast milk samples after two women injected their "usual" doses. In both milk and urine, methamphetamine is the predominant drug, with amphetamine being found in very small amounts in both. The half-lives of methamphetamine in breast milk were 13.6 and $7.4 \mathrm{~h}$. The total absolute infant dose of methamphetamine and amphetamine for both subjects, given in methamphetamine equivalents, were 17.5 and $44.6 \mu \mathrm{g} \mathrm{kg}^{-1} \mathrm{day}^{-1}$ during the first $24 \mathrm{~h}$ after use. Given that one tablet of Yaba weighs approximately $93 \mathrm{mg}$ and the average methamphetamine content is $22.8 \mathrm{mg}$ per $100 \mathrm{mg}$ of pill weight, this equates to about a third to half a tablet of Yaba daily which can be delivered to infants who are exclusively breastfed. Therefore, contrary to the WHO's recommendation regarding breastfeeding, it is an accepted practice at Siriraj Hospital to recommend withholding breastfeeding for up to $48 \mathrm{~h}$ in this particular group of mothers. The tradeoff is the missed opportunities for early mother-infant bonding through breastfeeding, which is a protective factor against abuse and neglect later on in life.

The adverse effects of methamphetamine exposure in utero and during infancy have been demonstrated. Intrauterine exposure causes decreased growth parameters of exposed newborns [8] as well the decreased growth trajectory in the first 3 years of life [10]. Infants that have been exposed to concurrent cigarette smoke as well as methamphetamine in utero are more likely to have intrauterine growth restriction. Other long-term consequences are neurobehavioral and include increased aggressive behavior, delayed acquisition of mathematics and language skills, and poorer visual recognition memory $[10,11]$.

\section{Neonatal Abstinence Syndrome}

In adults, methamphetamine withdrawal is characterized by increased sleeping and eating and depression-related symptoms. A similar abstinent syndrome of sleep disturbance, feeding intolerance, and irritability has been reported in infants exposed to methamphetamine in utero. The incidence can vary from as low as $2 \%$ to as high as $49 \%$ in some studies. However, unlike its cocaine 
counterpart, methamphetamine withdrawal in neonates rarely necessitates pharmacologic intervention $[8,11$, 12].

\section{Dextromethorphan: The Over-the-Counter High}

\section{History of Dextromethorphan in Thai Youths}

Unlike methamphetamine, the recreational use of DM in Thailand is a relatively new phenomenon. Its illicit use was first reported in Korea in 1998 and in the USA in 2000. However, to this author's knowledge, the first report of DM abuse in Thailand appeared in 2005 [13]. It is available as a $5-\mathrm{mg}$, single-product tablet. This, coupled with its low price of 1 THB per tablet (0.03 USD, 0.02 Euro, $0.02 \mathrm{GBP}$ ), has made it a very popular recreational drug among teens.

\section{Who Uses Dextromethorphan?}

Non-medical use of DM is prevalent among teenagers. The American Poison Control System reported a $300 \%$ increase in DM cases in teenagers 13-19 years of age in 2000-2003 [18]. In May 2010, a group of Thai middle school students procured DM tablets from an Internet game shop proprietor near their school. Over 80 students were involved in the incidence, with 44 being seen at a nearby hospital. The dose ingested varied from 0.3 to $9.8 \mathrm{mg} / \mathrm{kg}$. Of these, approximately $45 \%$ experienced tachycardia and vertigo, $27 \%$ had hypertension, and $11 \%$ experienced mental status changes (personal communications) [14]. In Thailand, the most common scenario for using DM is in a group situation where the drug is distributed among friends and several pills are mixed in soft drinks such as coke or orange juice [13]. Many teenagers feel that recreational use of dextromethorphan is a safe, viable alternative to other "illicit" recreational drugs such as ketamine or methamphetamine. Information available on the Internet regarding its low price, wide availability, lack of significant physical dependence, and withdrawal have encouraged the recreational experimentation of this drug [15].

Metabolism and Special Genetic Susceptibility

DM is converted by the CYP450 2D6 to three active metabolites in humans, namely, dextrophan, 3-hydroxymorphinan, and 3-methoxymorphinan. Of these, dextrophan has been the most extensively studied. Dextrophan is a more potent antagonist of the glutamate receptor $N$-methyl-D-aspartic acid (NMDA) which is responsible for the reported "positive" psychotropic effects. At very high doses, it can also produce sensation such as euphoria, distorted perception, and dissociative anesthesia that are seen with other NMDA antagonists such as PCP and ketamine. CYP 2D6 exhibits polymorphism in certain ethnic groups. Greater than $75 \%$ of Chinese-Asians have decreased CYP 2D6 activities and are poor metabolizers of the drug. The parent compound, DM, is known to increase central dopamine level as well acts as a weak serotonin reuptake inhibitor. Poor metabolizers, with increased DM level, often report more "negative" or undesirable effects such as intense hallucination, psychosis, and psychomotor disturbances, which are related to the dysregulation in the levels of dopamine and serotonin $[15,16]$.

\section{Clinical Presentation and Management}

The symptoms and toxicity of DM are dose-dependent. Patients present with a combination of sympathomimetic, psychedelic, and serotonin symptoms. Users often describe an "out of body experience" and present with pronounced tachycardia, hyperexcitability, and nystagmus. There can also be significant hypertension, hypertonia, and hyperthermia in very large overdoses and life-threatening symptoms such as stupor, coma, seizures; respiratory depression can also occur. The use of naloxone in treating respiratory depression from dextromethorphan overdose is still controversial. Some case reports suggest that repeated doses should be used if reversal of opioid toxicity does not occur, but no clear recommendation of dosing regimen exists $[15$, $17,18]$.

\section{Conclusion}

ATS and DM have gained unprecedented popularity as recreational drugs among Thai adolescents. Their effects, both short term and long term, are diverse depending on the drug, but in both cases can be permanent. Efforts must be made to control their distribution, abuse potential, and their far-reaching complications.

Conflict of interest There is no conflict of interest to report.

\section{References}

1. Wikipedia (2011) The history of Yaba (Thai Wikipedia). http://en. wikipedia.org/wiki/Ya ba. Accessed 17 November 2011

2. Greenfeld KT (2001) The need for speed. Times

3. UNODC (2011) World Drug Report 2011: United Nations Office on Drugs and Crime

4. Physical characteristics and major constituents of Yaba 2005. http://www.dmsc.moph.go.th/chiangmai/hotissue20.htm. Accessed 17 November 2011 
5. Sattah MV, Supawitkul S, Dondero TJ, Kilmarx PH, Young NL, Mastro TD et al (2002) Prevalence of and risk factors for methamphetamine use in northern Thai youth: results of an audiocomputer-assisted self-interviewing survey with urine testing. Addiction 97(7):801-808

6. Drugs of abuse report 2006-2009. Thanyarak Drug Rehabilitation Institute

7. Strang J, Griffiths P, Gossop M (1997) Heroin smoking by 'chasing the dragon': origins and history. Addiction 92(6):673-683, discussion 685-695

8. Chomchai C, Manorom NN, Watanarungsan P, Yossuck P, Chomchai $S$ (2004) Methamphetamine abuse during pregnancy and its health impact on neonates born at Siriraj Hospital, Bangkok, Thailand. Southeast Asian J Trop Med Public Health 35(1):228-231

9. Bartu A, Dusci LJ, Ilett KF (2009) Transfer of methylamphetamine and amphetamine into breast milk following recreational use of methylamphetamine. Br J Clin Pharmacol 67(4):455-459

10. Zabaneh R, Smith LM, LaGasse LL, Derauf C, Newman E, Shah $R$ et al (2011) The effects of prenatal methamphetamine exposure on childhood growth patterns from birth to 3 years of age. Am J Perinatol 28(9):1-8
11. Smith L, Yonekura ML, Wallace T, Berman N, Kuo J, Berkowitz C (2003) Effects of prenatal methamphetamine exposure on fetal growth and drug withdrawal symptoms in infants born at term. J Dev Behav Pediatr 24(1):17-23

12. McGregor C, Srisurapanont M, Jittiwutikarn J, Laobhripatr S, Wongtan T, White JM (2005) The nature, time course and severity of methamphetamine withdrawal. Addiction 100(9):1320-1329

13. Manaboriboon B, Chomchai C (2005) Dextromethorphan abuse in Thai adolescents: a report of two cases and review of literature. J Med Assoc Thai 88(Suppl 8):S242-S245

14. 80 Thai students in drug overdose scare 2011. AsiaOne

15. Banken JA, Foster H (2008) Dextromethorphan. Ann NY Acad Sci 1139:402-411

16. Zawertailo LA (2010) Effect of metabolic blockade on the psychoactive effects of dextromethorphan. Hum Psychopharmacol 25 (1):71-79

17. Kirages TJ, Sule HP, Mycyk MB (2003) Severe manifestations of coricidin intoxication. Am J Emerg Med 21(6):473-475

18. Kleinschmit KC, Wainscott M, Ford MD (2001) In: Ford MD (ed). Clinical toxicology: Chapter 77-Opiods. WB Saunders, Philadelphia 